\title{
In vitro Depth of Cure of Photo-activated Composites
}

\author{
R. TIRTHA, P.L. FAN, ${ }^{*}$ J.B. DENNISON, and J.M. POWERS
}

School of Dentistry, The University of Michigan, Ann Arbor, Michigan 48109, and *American Dental Association, Chicago, Illinois 60611

\begin{abstract}
The in vitro depth of cure of six photo-activated composites was studied by measurement of hardness, transverse strength, and light transmission coefficients. Both Barcol hardness and transverse strength were sensitive techniques for characterizing depth of cure. As a group, the visible light-activated composites had higher values of depth of cure and higher transmission coefficients than did the ultraviolet light-activated composites.
\end{abstract}

\section{J Dent Res 61(10):1184-1187, October 1982}

\section{Introduction.}

Photo-activated composite restorative materials offer the distinct clinical advantage of control over working time. Since photo-activated composites require no mixing at the time of insertion, there is also less potential for incorporation of air in the restoration. Concerns exist, however, about the depth of cure of photo-activated composites.

The in vitro depth of cure has been reported to be from 2 to $6 \mathrm{~mm}$ for ultraviolet light-activated composites, ${ }^{1-3}$ and from 2 to $8 \mathrm{~mm}$ for visible light-activated composites. ${ }^{3}$ Factors affecting depth of cure include chemical composition of the composite, ${ }^{2}$ mold materials and dimensions, ${ }^{3}$ and intensity of the light source. ${ }^{4}$ Depth of cure is also related to the transmission coefficient of the composite and the wavelength of the activating light, since these parameters affect the amount of light available in successive layers of the composite for activation of polymerization.

The purpose of this research was to study the in vitro depth of cure of six commercial photo-activated composites by measurement of hardness, transverse strength, and transmission coefficients.

\section{Materials and methods.}

The depth of cure of six commercial photo-activated composites was studied in vitro by measurement of the differences in hardness between the top and bottom surfaces and the transmission of light in samples of various thicknesses. Codes, shades, batch numbers, and manufacturers of the products tested are listed in Table 1.

Three samples $(10 \mathrm{~mm}$ in diameter) for each condition were prepared against a plastic matrix sheet in brass molds with thicknesses of $0.95,1.0$, and $1.35 \mathrm{~mm}$, and from 1.5 to $3.5 \mathrm{~mm}$ in increments of $0.5 \mathrm{~mm}$. Samples were cured using the recommended ultraviolet light $\left(\mathrm{W}^{+}, \mathrm{X}^{\dagger}\right)$ or

Received for publication November 9, 1981

Accepted for publication November 30,1981

This investigation was supported in part by Training Grant DE07101 from the National Institute of Dental Research, National Institutes of Health, Bethesda, MD 20205.

Request reprints from Dr. Dennison.

This investigation was presented at the 60th General Session of the International Association for Dental Research in New Orleans, LA, March, 1982.

+Nuva Lite, \#197 D, L.D. Caulk Co., Div. of Dentsply International, Inc., Milford, DE 19968

tLee Light, \#1209, Lee Pharmaceuticals, South E1 Monte, CA 91733

1184 visible light ( $\left.\mathrm{Y}^{+}, \mathrm{Z}^{\S}\right)$ sources for recommended times $(60$ s) with the light centered on the sample.

Barcol hardness readings ${ }^{\infty}$ were obtained for each sample three min after curing. Both top (nearest the light source) and bottom surfaces were tested in the center, and the difference in hardness $(\Delta H)$ between the two surfaces was calculated. Mean values of $\Delta H$ and standard deviations were determined. Data were analyzed by analysis of variance, 5 and mean values of $\Delta H$ were compared by Tukey intervals ${ }^{6}$ calculated at the $95 \%$ level of confidence.

Transverse strength was determined for composite $\mathrm{F}$ as a function of $\Delta H$ obtained under different conditions of sample thickness and application of light. Strength (S) was measured in transverse (three-point) bending with an apparatus as described elsewhere, ${ }^{7}$ and was calculated by $\mathrm{S}=3 \mathrm{PL} / 2 \mathrm{~b} \mathrm{x}^{2}$, where $\mathrm{P}$ is the load, 1 is the length (15 $\mathrm{mm}), \mathrm{b}$ is the width, and $\mathrm{x}$ is the thickness. Samples $(20$ $\mathrm{mm}$ in length and $2.5 \mathrm{~mm}$ in width) were prepared in dies $1.5,2.5$, and $3.0 \mathrm{~mm}$ thick, and were polymerized by two methods to vary the depth of cure: (1) by sweeping the light source across the sample length for $60 \mathrm{~s}$, or (2) by holding the light source in three adjacent spots for $60 \mathrm{~s}$ each. Values of $\Delta H$ were determined for these samples as already described. The data of $\mathrm{S} v s$. $\Delta H$ were analyzed by analysis of regression. ${ }^{8}$

Light transmission curves were obtained for uncured samples of composites ranging in thicknesses from 0.95 to $3.5 \mathrm{~mm}$ utilizing a double beam ultraviolet-visible spectrophotometer ${ }^{\text {I }}$ with an integrating sphere** as described elsewhere. ${ }^{9}$ Transmission spectra were obtained for visible light-activated composites between 400 and $700 \mathrm{~nm}$ and for ultraviolet light-activated composites between 285 and $400 \mathrm{~nm}$. Transmission coefficients were determined by measurement of intensities at $470 \mathrm{~nm}$ and $365 \mathrm{~nm}$, respectively, for the aforementioned composites as described below.

The intensity of a monochromatic beam of light passing through a translucent medium can be described by $I=I_{0}$ $t_{c}{ }^{x}$, where $I_{o}$ is the intensity of the incident beam, $I$ is the intensity of light after passing through a material of thickness $x$, and $t_{c}$ is the transmission coefficient defined as the ratio of $I / I_{O}$ when $x$ is a unit thickness. ${ }^{10}$ When $\log I / I_{0}$ is plotted as a function of $x$, the slope of the resulting line is $\log t_{c}$. Values of $\log t_{c}$ were determined by analysis of regression. 8

\section{Results.}

The differences in Barcol hardness $(\Delta H)$ between the top and bottom surfaces of the composites are plotted as a

\$Fotofil Light, \#1889, Johnson \& Johnson Dental Products Co., East Windsor, NJ 08520

\$Translux Light, \#2398, Reach Electronics, Inc., Lexington, NE 68850

${ }^{\infty}$ Barcol Indentor, Barber-Colman Co., Motor Division, Rockford, IL 61101

I ACTA C III UV-Visible Spectrophotometer, Beckman Instruments, Inc., Irvine, CA 92664

**ASPH-U Integrating Sphere, Beckman Instruments, Inc., Irvine, CA 92664 
TABLE 1

CODES, SHADES, BATCH NUMBERS, AND MANUFACTURERS OF PHOTO-ACTIVATED COMPOSITES STUDIED

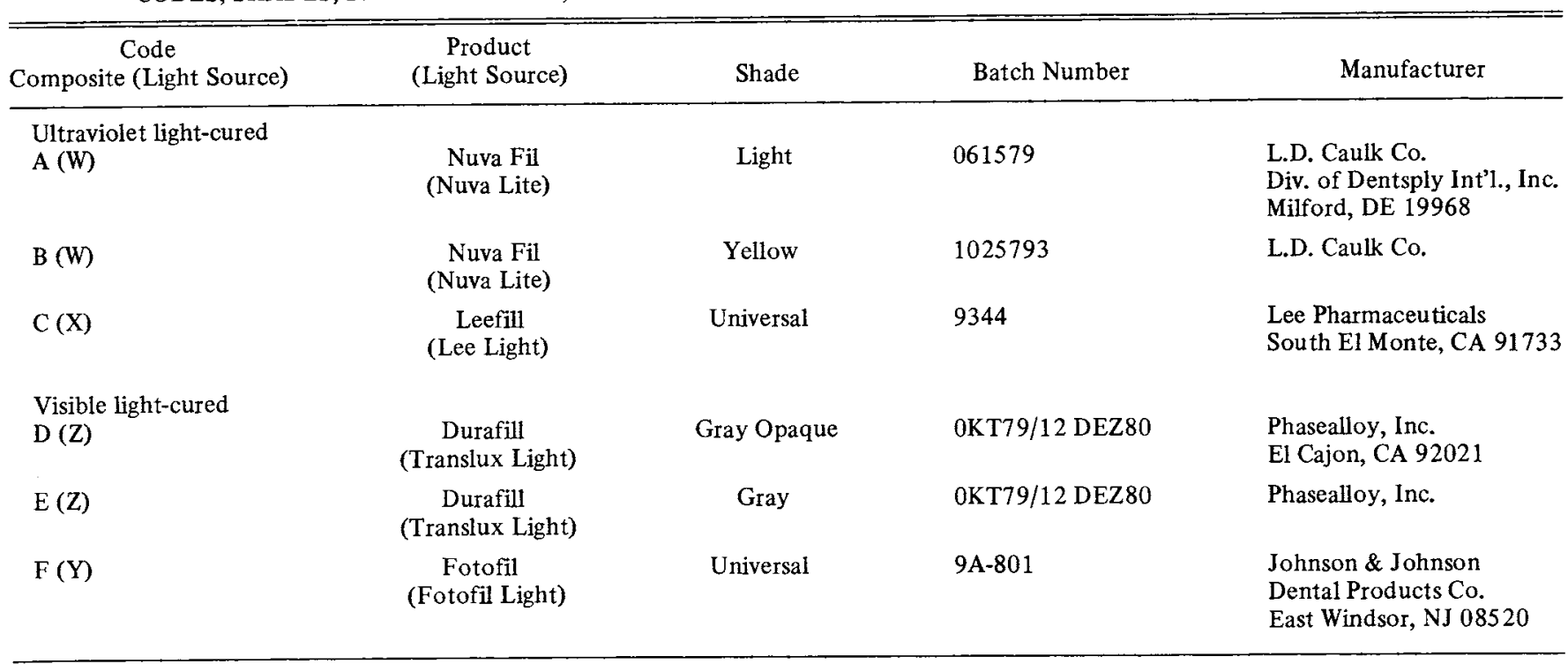

function of sample thickness $(x)$ in Fig. 1. The data were analyzed by analysis of variance, and a Tukey interval of 1.9 Barcol units was computed to show differences among means at different thicknesses. If $\Delta H$ of 5 Barcol units is considered to be a critical change in hardness, then corresponding values of critical depth of cure can be read from Fig. 1. These values are listed in Table 2 and varied from $1.4 \mathrm{~mm}$ for composite $\mathrm{B}$ to $2.7 \mathrm{~mm}$ for composite $\mathrm{F}$.

The transverse strength (S) of composite $\mathrm{F}$ was determined for 14 samples polymerized under different conditions to vary $\Delta H$. A plot of $\log S$ vs. $\Delta H$ is shown in Fig. 2. The correlation coefficient ( $\mathrm{r}$ ) of the line determined from analysis of regression was 0.960 . The critical value of $r$ above which the hypothesis of independence of $S$ and $\Delta H$ could be rejected was 0.532 at the $95 \%$ level of confidence. For $\Delta \mathrm{H}$ of 5 Barcol units, composite $\mathrm{F}$ decreased in strength from 82 to $71 \mathrm{MN} / \mathrm{m}^{2}$, a change of $13 \%$.

Plots of $\log \mathrm{I} / \mathrm{I}_{\mathrm{O}}$ vs. sample thickness $(\mathrm{x})$ for the composites are shown in Fig. 3. Slopes of these curves determined from linear regression are listed in Table 2 with the corresponding correlation coefficients. The transmission coefficients $\left(t_{c}\right)$ listed in Table 2 were calculated from these slopes as described. Values of $t_{c}$ ranged from $0.03 \mathrm{~mm}^{-1}$ for composite $B$ to $0.49 \mathrm{~mm}^{-1}$ for composite $F$.

The critical depth of cure determined from Fig. 1 by assuming a critical $\Delta \mathrm{H}$ of $5 \mathrm{Barcol}$ units is plotted as a function of the transmission coefficient $\left(t_{c}\right)$ of the composites in Fig. 4. The correlation coefficient determined from analy-

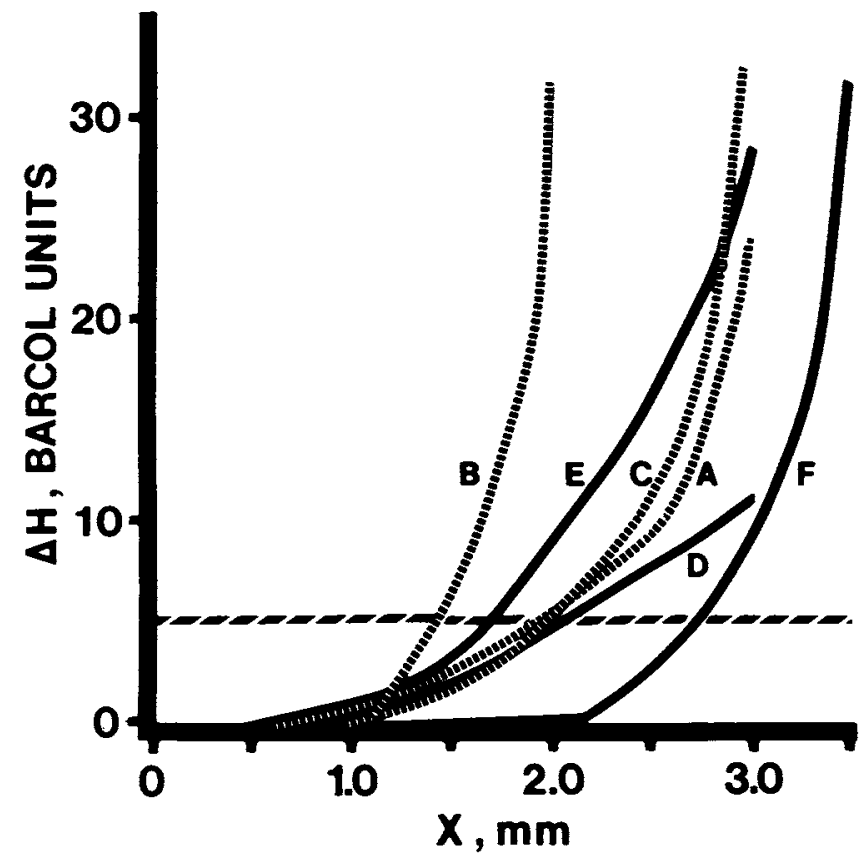

Fig. 1 - Graphs of differences in hardness $(\Delta \mathrm{H})$ between top and bottom surfaces of composite vs. thickness ( $\mathrm{x}$ ) of composite for six composites. The critical difference in hardness $(5$ Barcol units) is indicated by the broken line.

TABLE 2

CRITICAL DEPTH OF CURE AND TRANSMISSION COEFFICIENT FOR PHOTO-ACTIVATED COMPOSITES

\begin{tabular}{ccccc}
\hline Code & $\begin{array}{c}\text { Critical Depth } \\
\text { of Cure, }{ }^{*} \mathrm{~mm}\end{array}$ & $\begin{array}{c}\text { Slope of log } \mathbf{I} / \mathbf{I}_{\mathbf{o}} \\
\text { vs. } \mathrm{x}, \mathrm{mm}^{-1}\end{array}$ & $\begin{array}{c}\text { Correlation } \\
\text { Coefficient }\end{array}$ & $\mathrm{t}_{\mathrm{c}}, \mathrm{mm}^{-1}$ \\
\hline F & 2.7 & -0.313 & $0.998(0.811)$ & 0.49 \\
E & 1.7 & -0.552 & $0.997(0.878)$ & 0.28 \\
D & 2.1 & -0.589 & $0.998(0.878)$ & 0.26 \\
C & 2.0 & -0.690 & $0.986(0.754)$ & 0.20 \\
A & 2.0 & -1.158 & $0.927(0.878)$ & 0.07 \\
B & 1.4 & -1.520 & $0.956(0.950)$ & 0.03 \\
\hline
\end{tabular}

*Thickness at which $\Delta \mathbf{H}$ of $5 \mathrm{Barcol}$ units occurred.

$\dagger$ The critical value of $r$ for the $95 \%$ level of confidence is given in parentheses. 


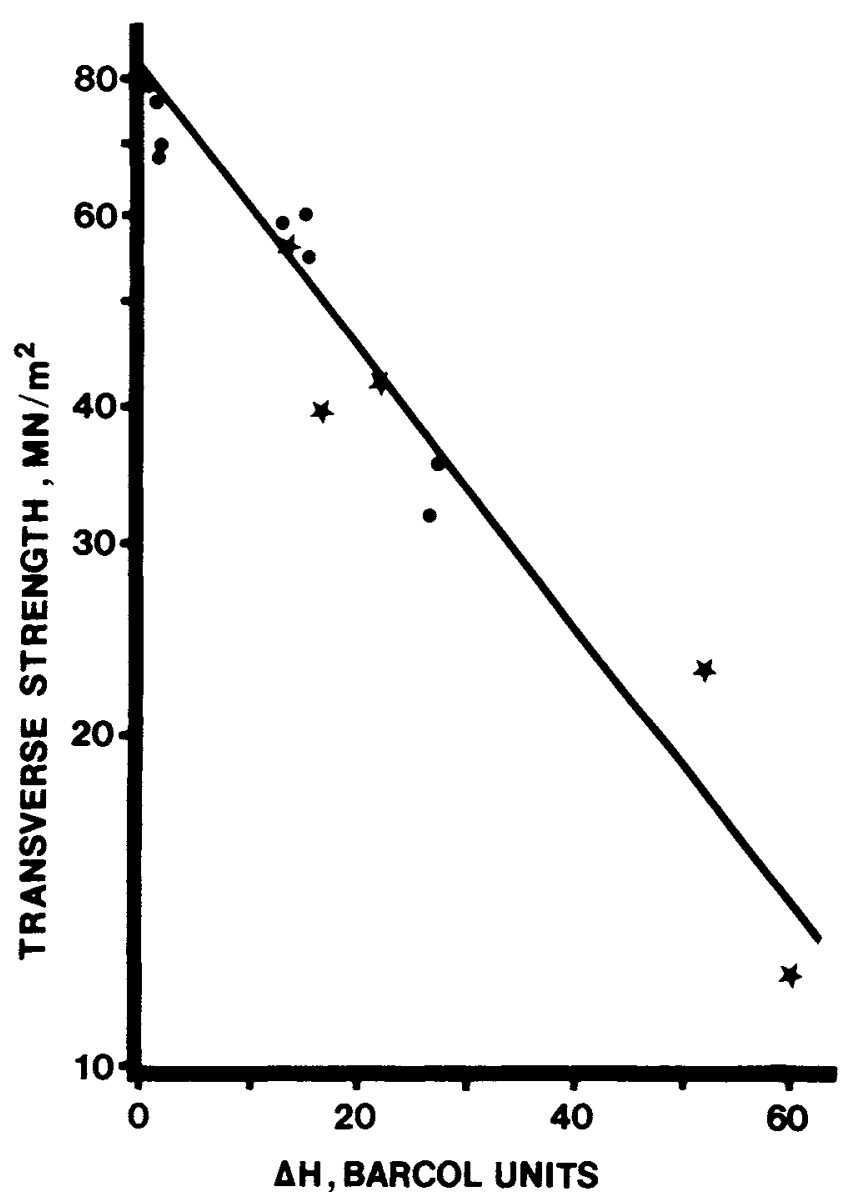

Fig. 2 - Graph of log transverse strength (S) vs. difference in hardness $(\Delta H)$ on a semi-log scale for 14 samples of composite $F$ polymerized under different conditions to vary $\Delta \mathrm{H}$. ${ }^{\bullet}$ represents data for light source held in three spots for $60 \mathrm{~s}$ each, whereas $\mathrm{x}$ represents data for light source sweeping for $60 \mathrm{~s}$.

sis of regression was 0.818 . The critical value of $r$ was 0.811 at the $95 \%$ level of confidence. As the transmission coefficient increased, the critical depth of cure also increased for the composites as a group, although there was a considerable amount of error (33\%) associated with the correlation.

\section{Discussion.}

The measurement of Barcol hardness of the top and bottom surfaces of a composite to evaluate depth of cure in vitro is a sensitive technique in which differences in hardness greater than 1.9 Barcol units are statistically significant. Values of critical depth of cure reported herein are in agreement with values reported by others ${ }^{1-3}$ using a scraping technique for samples made in a metal mold. Larger values of depth of cure would be expected for samples made in poly (tetrafluorethylene) molds. ${ }^{3}$ Correlations between these in vitro methods and in vivo results, however, have not been made.

The three-point bending test also appears to be a sensitive method to evaluate depth of cure of photo-activated composites. The inadequately polymerized bottom surface of a sample allows the knife edges of the sample holder to penetrate the sample. The load at failure is directly proportional to the actual thickness squared of the cured sample, whereas $\mathrm{x}$ (which includes both cured and uncured thicknesses) is used in computing the transverse strength (S).

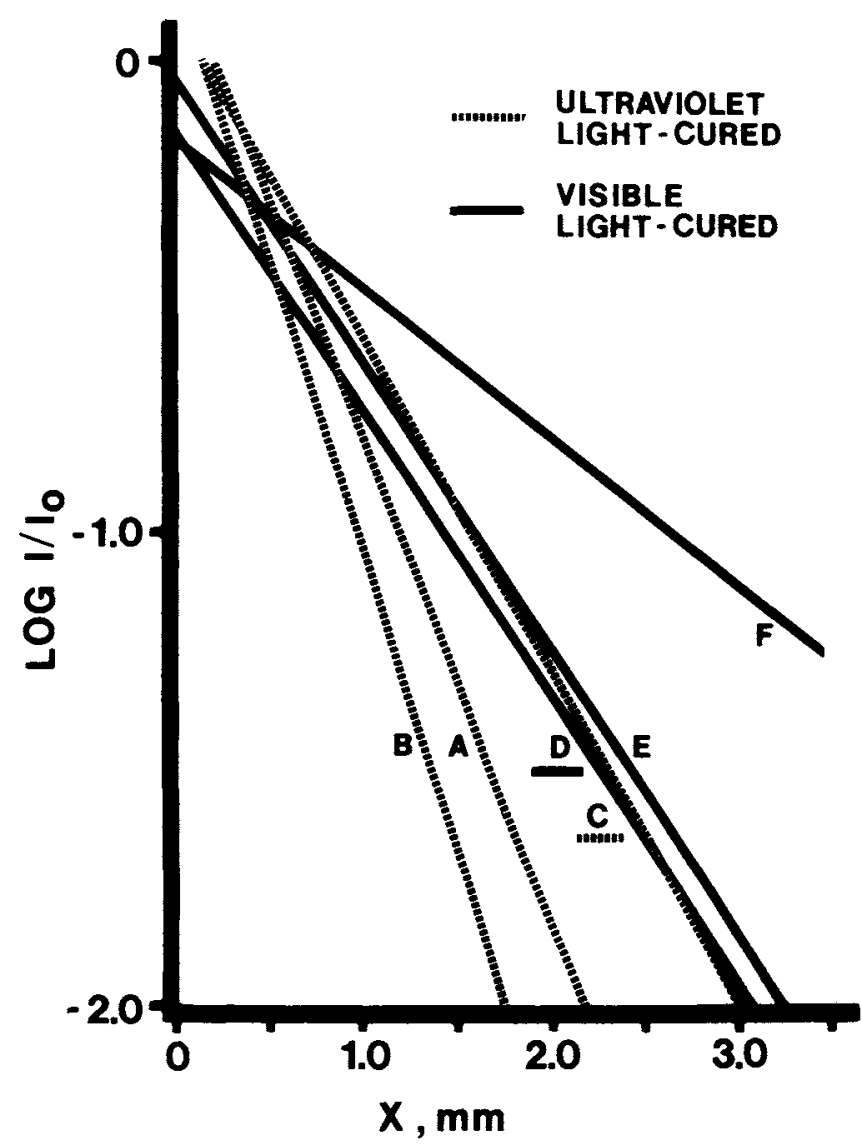

Fig. 3. - Graph of $\log I / I_{o}$ vs. thickness $(x)$ for six composites. The slope of each line is $\log t_{c}$. The values of $\log I / I_{o}$ of $0,-1$, and -2 represent values of $\mathrm{I} / \mathrm{I}_{\mathrm{o}}$ of $100 \%, 10 \%$, and $1 \%$, respectively.

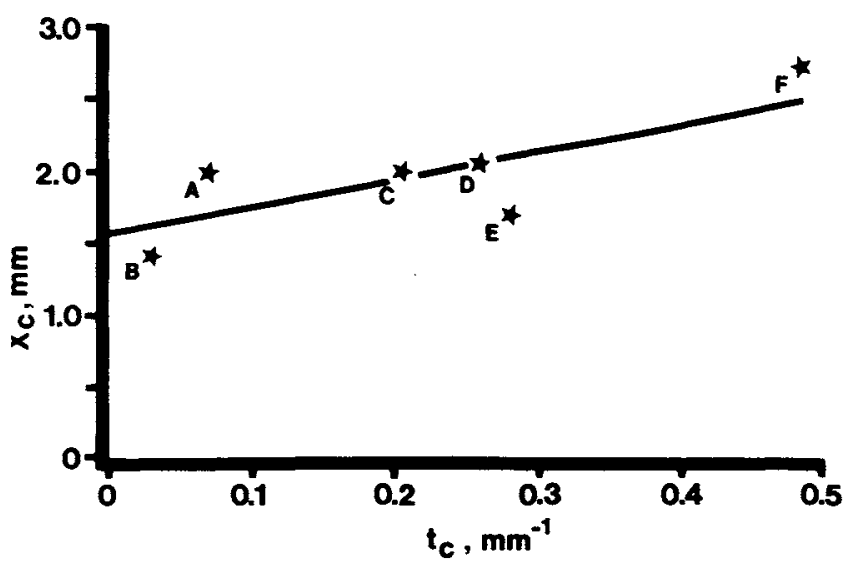

Fig. 4 - Graph of critical depth of cure $\left(\mathrm{x}_{\mathrm{c}}\right) v$ s. transmission coefficient $\left(t_{c}\right)$ for the photo-activated composites.

Composites with more shallow depths of cure would be expected to show larger decreases in transverse strength than would those with deeper depths of cure.

The visible light-activated composites (D, E, and F) as a group had higher values of critical depth of cure and higher transmission coefficients $\left(t_{c}\right)$ than did the ultraviolet lightactivated composites. The relatively poor correlation $(r=$ 0.818 ) between critical depth of cure and $t_{c}$ suggests that other factors are important in the polymerization process. 
Two factors are the type and concentration of the activatorinitiator system and the intensity of the light source used to polymerize the composite. It is expected that if these two factors were constant, then a higher depth of cure would result from a higher value of $t_{c}$. The transmission coefficient itself is influenced by the wavelength of light and by the refractive indices of the resin and fillers, as well as by the size, shape, and amount of filler particles. Thus, darker and more opaque shades of composites might be expected to have lower values of $t_{c}$. To offset a lower value of $t_{c}$, the manufacturer may adjust the activator-initiator.system to accommodate less light or recommend curing in thinner layers or for longer times.

Clinically, different shades of a manufacturer's photoactivated composite may require different curing techniques. Application of the composite in layers and adjustment of the exposure time or intensity of the light source may be necessary to polymerize some shades of composite completely, compared to the universal shade for which curing conditions are usually well-defined. Since the ultraviolet light-cured composites have low values of the transmission coefficient, curing of these composites should be given extra attention.

\section{Conclusions.}

The depth of cure of six photo-activated composites was studied in vitro by measurement of hardness, transverse strength, and transmission coefficients. Barcol hardness was a sensitive technique for evaluation of depth of cure. A difference in hardness between the top and bottom surfaces of one composite of $5 \mathrm{Barcol}$ units was equivalent to a $13 \%$ decrease in transverse strength. As a group, the visible lightactivated composites had higher values of depth of cure and higher transmission coefficients than did the ultraviolet light-activated composites.

\section{Acknowledgments.}

The cooperation of Johnson \& Johnson Dental Products Co., Lee Pharmaceuticals, L.D. Caulk Co., and Phasealloy, Inc., for supplying commercial products used in this study is acknowledged.

\section{REFERENCES}

1. ABELL, A.K.; LEINFELDER, K.F.; and TURNER, D.T.: Range of Photopolymerization of Composite Tooth Restorative Materials, IADR Progr \& Abst 58:No. 667, 1979.

2. COOK, W.D.: Factors Affecting the Depth of Cure of UVpolymerized Composites, J Dent Res 59:800-808, 1980.

3. KILIAN, R.J. and MULLEN, T.J.: Light-cured Composites: Dependence of Test Results on Test Parameters, IADR Progr \& Abst 59:No. 203, 1980.

4. KILIAN, R.J.: Visible Light-cured Composites: Dependence of Cure on Light Intensity, IADR Progr \& Abst 58:No. 603, 1979.

5. DALBY, J. (programmer): BMD8V - Analysis of Variance, Ann Arbor: Statistical Research Laboratory, University of Michigan, 1968, 4 pp.

6. GUENTHER, W.C.: Analysis of Variance, Englewood Cliffs, NJ: Prentice-Hall, 1964, 199 pp.

7. ROBERTS, J.C.; POWERS, J.M.; and CRAIG, R.G.: Fracture Toughness of Composite and Unfilled Restorative Resins, $J$ Dent Res 56:748-753, 1977.

8. A Manual of Elementary Statistics Using MIDAS, Ann Arbor: Statistical Research Laboratory, University of Michigan, 1975, $301 \mathrm{pp}$.

9. BRODBELT, R.J.W.; O'BRIEN, W.J.; and FAN, P.L.: Translucency of Dental Porcelain, J Dent Res 59:70-75, 1980.

10. MORGAN, J.: Introduction to Geometric and Physical Optics, New York: McGraw-Hill, 1953.

\title{
1983 IADR ABSTRACT PACKETS AVAILABLE
}

Abstract packets for IADR's 1983 meeting (August 1-3, Sydney, Australia) are now available from the Central Office. Postcards were mailed to all IADR members (except those in the ANZ Division*) in mid-July, notifying them of this availability. If you would like an abstract packet for this meeting, either contact the Central Office or your Divisional Secretary. Or, simply sign and return the postcard, in an envelope, to the Central Office. Deadline for receipt of these abstracts is January 25, 1983. PLEASE DO NOT USE AN AADR ABSTRACT FORM TO SUBMIT FOR THE SYDNEY MEETING.

\author{
Note: Individuals interested in presenting \\ papers at both the ICOB and IADR \\ meetings in Sydney next August will \\ be permitted to do so, provided that \\ the material presented is different at \\ each meeting.
}

For US NIDR grantees only: A Travel Assistance Grant has been funded to assist US NIDR grantees presenting at the Sydney meeting. Grants will be awarded in accordance with criteria determined by the AADR Program Committee. A list of these criteria is available from the IADR Central Office. Funding will be used to pay air travel costs only. If you are eligible for an NIDR Travel Assistance Grant, please complete the appropriate items on the abstract form when you submit.

*Each individual member of the ANZ Division will receive a complete abstract packet. 